\title{
Haematological Studies on Multiple Squamous Cell Carcinoma Patients in Nigeria
}

\author{
Obeagu Emmanuel Ifeanyi ${ }^{1,2 *}$, Okorie Hope $\mathbf{M}^{2}$, Obeagu Getrude Uzoma ${ }^{3}$ and Anaebo Queen Braxton $\mathrm{N}^{4}$ \\ ${ }^{1}$ Medical Laboratory Science, University Health Services, Michael Okpara University of Agriculture, Nigeria
}

${ }^{2}$ Department of Medical Laboratory Science, Imo State University, Nigeria

${ }^{3}$ Department of Nursing Science, Ebonyi State University, Nigeria

${ }^{4}$ Department of Accident/Emergency, Lagos University Teaching Hospital, Nigeria

*Corresponding author: Obeagu Emmanuel Ifeanyi, Medical Laboratory Services, University Health Services, Michael Okpara University of Agriculture, Umudike, Abia State, Nigeria

\begin{abstract}
Multiple squamous cell carcinomas (MSCCs) in albinos occur mainly due to light melanin and constant exposure to ultraviolet rays of sun light. A study to evaluate changes in haematological parameters was done in albinos with multiple squamous cell carcinomas in a tertiary health institution in Enugu, Nigeria. A total of 40 subjects were recruited for the study comprising 20 subjects each for MSCC and control. About $2 \mathrm{ml}$ of venous blood was collected by venepuncture into EDTA anticoagulated containers and Mindray BC-5300 used to measure the haematological parameters. The data were analysed using SPSS version 21 with t-test and significance level set at $\mathrm{P}<0.05$. The results showed increase in ESR $(19.80 \pm 3.40 \mathrm{~mm} / \mathrm{hr}, 6.80 \pm 2.33 \mathrm{~mm} / \mathrm{hr}, 0.000)$, WBC $(5.91 \pm 0.45 X 109 / \mathrm{L}, 4.65 \pm 0.59 X 109 / \mathrm{L}, \mathrm{P}=0.000)$, Eosinophils $(4.06 \pm 1.03 \%, 0.54 \pm 0.50 \%, \mathrm{P}=0.000)$ and Monocytes $(5.53 \pm 1.18 \%$, $1.53 \pm 0.51 \%, \mathrm{P}=0.000)$, decrease in platelets $(182.13 \pm 41.31 \mathrm{X} 109 / \mathrm{L}, 226.26 \pm 25.13 \mathrm{X} 109 / \mathrm{L}, \mathrm{P}=0.001)$ and no significant difference $(\mathrm{P}>0.05)$ in RBC $(4.60 \pm 0.30 \mathrm{X} 1012 / \mathrm{L}, 4.79 \pm 0.38 \mathrm{X} 1012 / \mathrm{L}, \mathrm{P}=0.133)$, Haemoglobin $(13.80 \pm 0.89 \mathrm{~g} / \mathrm{dl}, 14.40 \pm 1.16 \mathrm{~g} / \mathrm{dl}, \mathrm{P}=0.121)$, PCV $(41.40 \pm 2.66 \%, 43.20 \pm 3.50 \%, P=0.125)$ and lymphocytes $(48.53 \pm 6.46 \%, 45.12 \pm 5.09 \%, P=0.120)$ of MSCC subjects compared to control respectively. The RBC, Haemoglobin and packed cell volume were not affected with this cancer but platelets, WBC, monocytes, eosinophils, neutrophils showed changes that were statistically significant. The clinicians and all the health practitioners involved with the management of albinos with MSCC should monitors these changes and also be careful to avert cardiovascular disease due to shift in neutrophils to lymphocytes ratio.
\end{abstract}

Keywords: Haematological studies; Multiple squamous cell carcinoma patients; Nigeria

\section{Introduction}

Multiple squamous cell carcinomas (MSCCs) involve a lot of varied types of cancer that originate from squamous cells [1]. These cells make up the outer parts of skin and lining of some organs, respiratory and digestive tracts [1]. It has been reported that cancer may be regarded as a very large and exceptionally heterogeneous family of malignant diseases with squamous cell carcinomas comprising one of the largest subsets [2-4].

Cancer has been a public global health challenge with increased morbidity and mortality rates across the world. Cancer demands much attention as many a times are not diagnosed early and managed at the stage it can be controlled. Cancer presents with a lot of challenges including bleeding, pains, loss of weight, fever and so many other features that are excruciating and debilitating. Haematological parameters are good indicators of health and disease status [5,6]. It is important to consider studies in haematological parameters to ascertain the levels of alterations in these aspects of Laboratory Medicine that are crucial in wellbeing of the patients. There is strong evidence between diet and exposure of the skin to sunlight especially ultraviolet rays and MSCC $[7,8]$. The increased intake of high fat dairy foods increases MSCC tumor risk especially with person with history of skin cancer. Smoking, high beer and liquor consumption increase the risk of MSCC [9]. The study was done to determine haematological parameters of multiple squamous cell carcinoma patients in Nigeria

\section{Materials and methods}

\section{Study area}

The study was done in National Orthopedic Hospital, Enugu, Nigeria. 


\section{Subjects}

A total of 40 subjects were recruited for the study comprising 20 subjects each for Multiple squamous cell carcinoma (MSCC) and apparently healthy subjects (Control) blood group who were apparently healthy individuals drawn from the Health institution.

\section{Sample collection}

About $2 \mathrm{mls}$ of venous blood was collected from the subjects into anticoagulated containers for haematological parameters determination.

\section{Laboratory investigations}

The hematological parameters were determined using Mindray BC-5300. The haematological parameters investigated include WBC, Neutrophils, Lymphocytes, Monocytes, Red Blood Cells, Hemoglobin, Packed Cell Volume, Platelets and Erythrocyte Sedimentation Rate (ESR).

\section{Ethical Consideration}

The details of the research were explained to the subjects and written consents obtained from them and were assured of joining the study willingly and confidentiality also assured. The subjects who gave their consents were allowed to participate in the study.

\section{Statistical Analysis}

The results were expressed as mean \pm standard deviation. The data were analysed with the statistical package for social science (SPSS) version 20 using t-test, ANOVA and the level of significance was set at $\mathrm{P}<0.05$.

Table 1: Mean \pm sd values of haematological parameters of MSCC and control subjects

\begin{tabular}{|c|c|c|c|}
\hline Parameters & MSCC & CONTROL & P-VALUE \\
\hline RBC $(\mathrm{X} 109 / \mathrm{L})$ & $4.60 \pm 0.30$ & $4.79 \pm 0.38$ & $0.133 \mathrm{NS}$ \\
\hline Haemoglobin (g/dl) & $13.80 \pm 0.89$ & $14.40 \pm 1.16$ & $0.121 \mathrm{NS}$ \\
\hline PCV (\%) & $41.40 \pm 2.66$ & $43.20 \pm 3.50$ & $0.125 \mathrm{NS}$ \\
\hline ESR (mm/hr) & $19.80 \pm 3.40$ & $6.80 \pm 2.33$ & $0.000^{*}$ \\
\hline Platelets(X109/L) & $182.13 \pm 41.31$ & $226.26 \pm 25.13$ & $0.001^{*}$ \\
\hline WBC(X109/L) & $5.91 \pm 0.45$ & $4.65 \pm 0.59$ & $0.000^{*}$ \\
\hline Neutrophils(\%) & $41.86 \pm 6.73$ & $52.80 \pm 4.95$ & $0.000^{*}$ \\
\hline Lymphocytes (\%) & $48.53 \pm 6.46$ & $45.12 \pm 5.09$ & $0.120 \mathrm{NS}$ \\
\hline Eosinophils(\%) & $4.06 \pm 1.03$ & $0.54 \pm 0.50$ & $0.000^{*}$ \\
\hline Monocytes(\%) & $5.53 \pm 1.18$ & $1.53 \pm 0.51$ & $0.000^{*}$ \\
\hline
\end{tabular}

Significant level $-{ }^{*} \mathrm{P}<0.05$,

ns

- Not significant $(\mathrm{P}>0.05)$

The results showed increase in ESR $(19.80 \pm 3.40 \mathrm{~mm} / \mathrm{hr}$, $6.80 \pm 2.33 \mathrm{~mm} / \mathrm{hr}, 0.000)$, WBC $\left(5.91 \pm 0.45 \mathrm{X} 10^{9} / \mathrm{L}, 4.65 \pm 0.59\right.$ $\mathrm{X} 10^{9} / \mathrm{L}, \mathrm{P}=0.000$ ) , Eosinophils (4.06 $\pm 1.03 \%, 0.54 \pm 0.50 \%, \mathrm{P}=0.000$ ) and Monocytes $(5.53 \pm 1.18 \%, 1.53 \pm 0.51 \%, P=0.000)$, decrease in platelets $\left(182.13 \pm 41.31 \mathrm{X} 10^{9} / \mathrm{L}, \quad 226.26 \pm 25.13 \mathrm{X} 10^{9} / \mathrm{L}, \mathrm{P}=\right.$ $0.001)$ and no significant difference $(P>0.05)$ in RBC $(4.60 \pm 0.30$ $\left.\mathrm{X} 10^{12} / \mathrm{L}, 4.79 \pm 0.38 \times 10^{12} / \mathrm{L}, \mathrm{P}=0.133\right)$, Haemoglobin $(13.80 \pm 0.89 \mathrm{~g} /$ dl, $14.40 \pm 1.16 \mathrm{~g} / \mathrm{dl}, \mathrm{P}=0.121)$, PCV $(41.40 \pm 2.66 \%, 43.20 \pm 3.50 \%$, $\mathrm{P}=0.125)$ and lymphocytes $(48.53 \pm 6.46 \%, 45.12 \pm 5.09 \%, \mathrm{P}=0.120$ of MSCC subjects compared to control respectively (Table 1).

\section{Discussion}

Multiple squamous cell carcinoma (MSCC) of the skin is an extensively rare entity but may be more in albinos because of their melanin level of their skin. It is associated with ultraviolet radiation, immunodeficiency states, local intramuscular metastasis and cell carcinoma [10]. The study of haematological parameters of albino patients with multiple squamous cell carcinomas showed increase in erythrocyte sedimentation rate (ESR). Although, ESR has been reported as nonspecific diagnostic tool but may aid in the diagnosis of MSCC as the increase was statistically significant compared to the levels in apparently healthy age and sex matched subjects. Patients with multiple squamous cell carcinomas have a significantly increased risk of developing a recurrence or spread to their lymph nodes, warranting frequent follow up visits to their dermatologists. Cutaneous squamous cell carcinoma when diagnosed and treated early is highly curable [11]. Albino subjects are easily affected by much exposure to sunlight and MSCC is seen on their skin not always covered against ultraviolet rays of the sun. It shows that MSCC elevates the levels of ESR in the patients which may affect the viscosity of their blood and osmotic fragility of the blood. The study also showed increase in WBC of MSCC patients relative to the control. This could be linked to increased oxidative stress among the patients. There could be increased generation of free radical and reactive oxygen species in the MSCC patients due to increased metabolism and stress and a lot of acute infections that resulted in the increase in the WBC. The study showed increase in eosinophils showing that there could be hypersensitivity reactions. That shows that MSCC is associated to allergens. The eosinophils increased significantly. The study also showed increase in monocytes. This 
shows that MSCC may have intracellular association with some infections and release of cytokine linked to this increased levels of monocytes. There was a shift in neutrophils to lymphocytes ratio which could point to risk of vadiovascular diseases in patients with MSCC. This shows that the body may utilize more of antibody mediated immunity than cell mediated immunity.

Haematological parameters have been reported as good indicators for health and disease status of patients [5,6]. The study revealed no significant difference in RBC, haemoglobin and packed cell volume together with lymphocytes. This shows that patients with MSCC may not suffer from anemia. The carcinoma may not suppress bone marrow activity. Those involved with the management of MSCC should be mindful of these changes especially in the WBC, eosinophils, neutrophils, erythrocyte sedimentation rate (ESR) and platelets. There may not be bleeding as seen in other cancers as the platelets were not low but decreased when compared to the control.

\section{Conclusion}

Cancer is a major global public health issue challenging the whole world with increased morbidity and mortality. Multiple squamous cell carcinomas could be neglected cancer diseases that are more common to albinos due to their melanin levels in the skin and constant exposure to ultraviolet radiation from sun light in the parts of their body not always covered with dress. The RBC, Haemoglobin and packed cell volume were not affected with this cancer but platelets, WBC, monocytes, eosinophils, neutrophils showed changes that were statistically significant. The clinicians and all the health practitioners involved with the management of albinos with MSCC should monitors these changes and also be careful to avert cardiovascular disease due to shift in neutrophils to lymphocytes ratio.

\section{References}

1. NCI (2011) Dictionary of Cancer Terms. National Cancer

2. Berman JJ (2004) Turnover Taxonomy for the development lineage classification of neoplasms. BMC Cancer 4(1): 88.

3. Berman JJ (2004) Turnover classification: molecular analysis meets Aristotle. BMC Cancer 4(1): 10.

4. Travis WD, Brambilla E, Muller Hermelink, HK Harris, CC eds (2004) Pathology and Genetics of Tumors of the Lung Pleura, Thymus and Heart. World Health Organization Classification of Tumors.

5. Obeagu E, Obeagu GU, Chijioke UO and Ofor IB (2017) Analysis of Alterations in Selected Haematological Parameters of Ascariasis Patients in Umudike, Abia State, Nigeria. Ann Clin Lab Res 5(3): 193.

6. Obeagu EI, Azuonwu O, Didia BC and Obeagu GU (2018) Determination of Haematological Changes Associated with Syphilis in Subjects in Umudike, Abia State, Nigeria. Cohesive Journal of Microbiology and Infectious Disease 1(1): 505.

7. De Stefani E, Deneo Pellegrini H, Ronco AL, Boffetta P, Brennan P, etal. (2003) Food groups and risk of squamous cell carcinoma of the oesophagus: a case- control study in urology. British Journal of Cancer 89(7): 1209-1214.

8. Chen YK, Lee CH, Wu IC, Liu JS, Wu DC, et al. (2009) Food intake and the Occurrence of squamous cell carcinoma in different sections of the esophagus in Taiwanese Men. Nutrition 25(7-8): 753-761.

9. Bahmanyar S, Ye WL (2006) Dictionary Patterns and Risk of Squamous cell Carcinoma and Adenocarcinoma f the Gastric Cardia: A Populationbased Case Control Study in Sweden. Nutrition and Cancer 54(2): 171178

10. Kaur J, Sharma N, Sharma S (2012) Multiple Cutaneous Squamous Cell Cracinoma: Primary Carcinomas versus Cutaneous Metastasis. J Can Res Ther 8(2): 300-302.

11. Levine D, Kari P, Schumults C (2015) Outcomes of Patients with Multiple Cutaneous Squamous Cell Carcinomas: A 10 Year Single Institution Cohort Study. JAMA Dermatology 17(2).

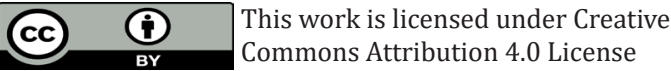

To Submit Your Article Click Here: Submit Article

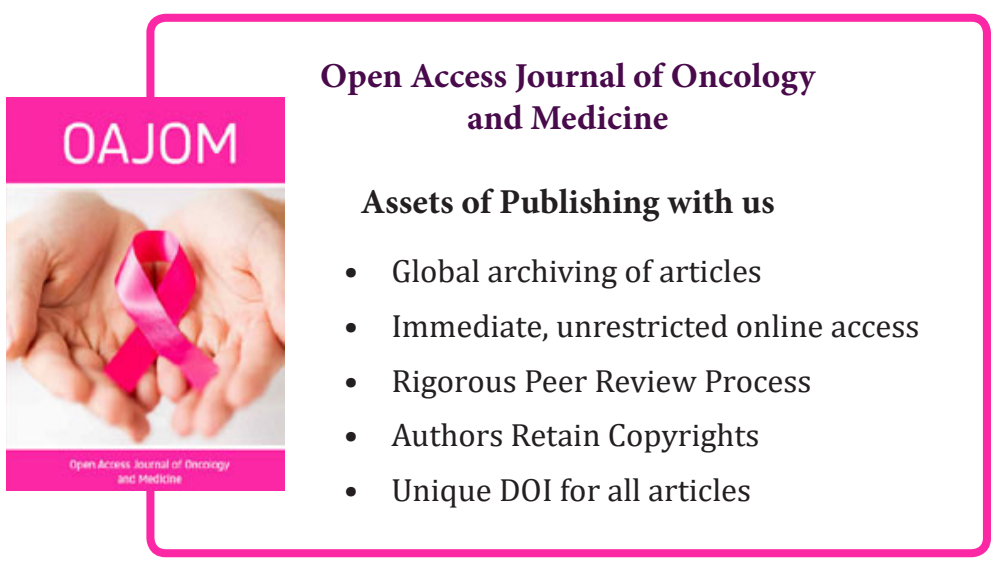

Citation: Obeagu Emmanuel Ifeanyi*, Okorie Hope M, Obeagu Getrude Uzoma, Anaebo Queen Braxton N. Haematological Studies on 